\title{
PULVERIZED COAL COMBUSTION ADVANCED CONTROL TECHNIQUES
}

\author{
Konrad Gromaszek \\ Lublin University of Technology, Faculty of Electrical Engineering and Computer Science
}

Abstract. The paper describes the selected methods of adaptive control of the pulverized coal combustion process overview with various types of prognostic models. It was proposed to use a class of control methods that are relatively well established in industrial practice. The presented approach distinguishes the use of an additional source of information in the form of signals from an optical diagnostic system and models based on selected deep structures of recurrent networks. The research aim is to increase the efficiency of the combustion process in the power boiler, taking into account the EU emission standards, leading in consequence to sustainable energy and sustainable environmental engineering.

Keywords: combustion control, adaptive algorithms, artificial neural networks

\section{ZAAWANSOWANE METODY STEROWANIA PROCESEM SPALANIA PYLU WEGLOWEGO}

Streszczenie. W artykule opisano wybrane metody adaptacyjnego sterowania przeglądem procesu spalania pylu węglowego z wykorzystaniem określonych modeli prognostycznych. Zaproponowano użycie metod, które sa stosunkowo dobrze znane w praktyce przemystowej. Przedstawione podejście wyróżnia wykorzystanie dodatkowego źródła informacji w postaci sygnałów z optycznego systemu diagnostycznego i modeli opartych na strukturach sieci głębokich. Badania mają na celu zwiększenia efektywności procesu spalania w kotle energetycznym, z uwzględnieniem norm emisji UE, prowadząc w konsekwencji do zrównoważonej energii i zrównoważonej inżynierii środowiska.

Slowa kluczowe: sterowanie procesem algorytmy adaptacyjne, sztuczne sieci neuronowe

\section{Introduction}

The combustion process, as already mentioned, in particular, carried out in industrial conditions, is characterized by very high complexity. This is due to the nature of the phenomena accompanying the process as well as the difficult measurement conditions, including the unavailability of specific quantities and the impact of high temperature, vibration, and dustiness on measuring and recording devices. The issues discussed in this monograph, regardless of trends in the pulverized coal combustion in the power industry, raise a number of intensive issues, developed many research works. It attempts to control one of the most challenging processes using analytical, heuristic and hybrid methods. The conducted research is in line with the directions of searching for algorithms for non-linear processes that will be numerically reliable, robust and, above all, will allow meeting technological limitations in the conditions of the uncertainty of model parameters

\section{Combustion process modelling}

In commercial power plants, many subsystems can be distinguished, which include: supply of fuel, water, fuel combustion (combustion chamber), steam generating system, turbine and generator system, and boiler safety system. Hence, developing a holistic (comprehensive) model of such a complicated process is a tough challenge. For this reason, in general, decomposition takes place, i.e., a division into smaller parts, describing specific subsystems or modules, due to the implemented functions or specific tasks. An unquestionable advantage of modularity is the simplification of the analysis and validation of the proposed solutions. The starting point for the classical mathematical model's development is the description of the physical and physicochemical phenomena of a given system using the principle of energy conservation, thermal balance and mass balance [7]. Based on the mathematical description of the phenomena occurring in the boilers [8], a mathematical model of the combustion chamber was developed and used to compare various constructional solutions. Unfortunately, in most cases, there was a lack of consistency between the measurement data for specific measurement conditions and the variables necessary for the model use. This required further research in the field of parametric identification of the process based on the collected data.

In the practical diagnostics and control algorithms, the detailed and simultaneously noncompliant models are desirable, due to the strong non-linearity, complexity and high dynamics of the combustion process. The heuristic methods presented in the monograph allow for effective finding approximate solutions, from which the final result is calculated later. The limitation of these solutions is the lack of direct knowledge about the state of the model and the lack of knowledge about the response of the neural model to the non-standard range of input signals. Lack of direct knowledge about the model's condition and lack of knowledge about the neural model's response to the non-standard range of input signals is a limitation of this type of solution.

This mainly applies to methods of deep learning. In addition to class selection, structure and learning methods, there are also opportunities to influence the learning process through regularization techniques and more effective activation functions. Recursive neural networks (RNNs) are modelled on the behaviour of many occurring in nature many cells with content-addressable memory, capable of capturing the whole sequence of information, given as fragments. While forward networks trigger their neurons in one direction, RNNs use strong feedback. RNNs model non-linear dynamic systems whose phase space dynamics is determined by a significant number of locally stable nodes [4].

During long-term context storage, RNN gradients can become difficult to remove because they use their feedback to memorize the structure of the last inputs. Similarly, backwardly propagating error signals over time can have large values (causing oscillations of weights) or recede (making it difficult to determine slowchange weights). These changes during the backward propagation errors depend exponentially on the value of the weights $[1,2]$.

\section{Modern approaches}

The classic structure of a multi-layer perceptron and the long short-term memory (LSTM) was used for neural combustion process modelling in the monograph The advantage of LSTM is that it truncates gradients in the network, wherever it is harmless, and at the same time enforces continuous error flows in individual multiplicative units (MUs). The continuous error flow is regulated by nonlinear MUs that learn to open or close gates in a cell. The diagram of such a structure is shown in Figure 1.

They are structures whose forgetting gates allow for precise learning in time.

The analysis of the combustion process in coal-fired boilers reveals three main factors that adversely affect the boiler efficiency. These include the level of slagging and contamination of heating surfaces and measuring instruments, heat losses due to exhaust gases as well as a large share of unburnt coal. The possibility of assessing combustion quality is significant for proper operation of the power boiler [6]. Considering the combustion process in pulverized coal boilers, it should be noted that: chemical reactions, heat transfer efficiency, flame stability as well as the intensity of NOx and CO formation have the significant influence on it. The burners and the fuel delivery method have a crucial influence on 
the combustion aerodynamics. Low-emission coal burners use the reduction properties of a rich pulverized coal flame by organizing sub-stoichiometric combustion zones using air staging or fuel staging. This, in turn, may worsen the combustion stability and increase the loss of the flame.

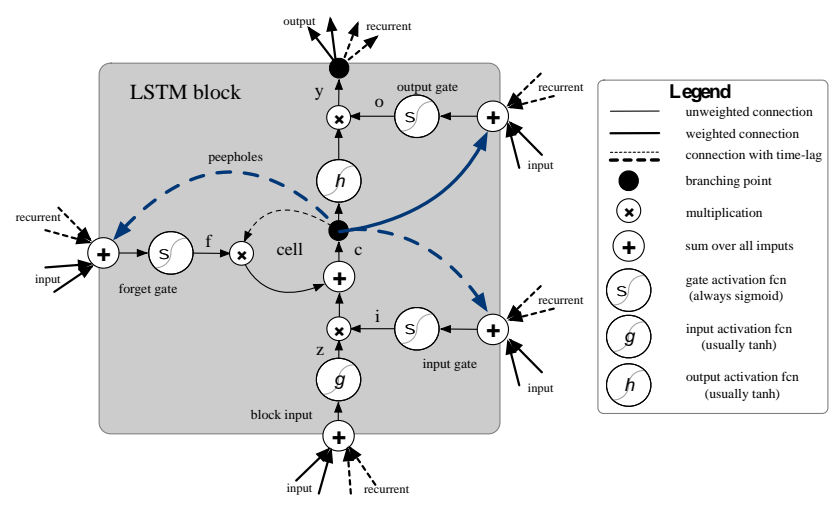

Fig. 1. The Long Short-Term Memory (LSTM) single cell model

Taking into account these factors and significant ecological aspects, there is a need to develop a combustion process control system that will optimize boiler operation based on information obtained from conventional equipment and will take into account innovative techniques to assess the quality of the process. From the technological side, an important parameter is to ensure flame stability and detection of emergency states. Therefore, the control system should be enriched with flame diagnostic information using vision technologies or fiber optic probes. Quantitative information on the concentration of nitrogen oxides, carbon oxides, and sulphur dioxide is equally essential in order to meet normative limitations.

Continuous measurement of the dust flow in dust-conductors will undoubtedly bring valuable information about the input parameters of the process, but it is difficult to measure. Similarly considering the process output, it would be crucial to obtain information online about the content of flammable parts in ash and slag (especially the organic carbon content). To obtain this information, it is necessary to carry out measurements on the real object using expensive measuring equipment.

The use of this information in the solutions proposed in the monograph was possible thanks to the research carried out at the Institute of Power Engineering in Warsaw, on the experimental stand for testing the combustion process with a heat output of 0.5 MW using a coal burner. The layout of the station, in the configuration for the co-firing process testing, is shown in Figure 2.

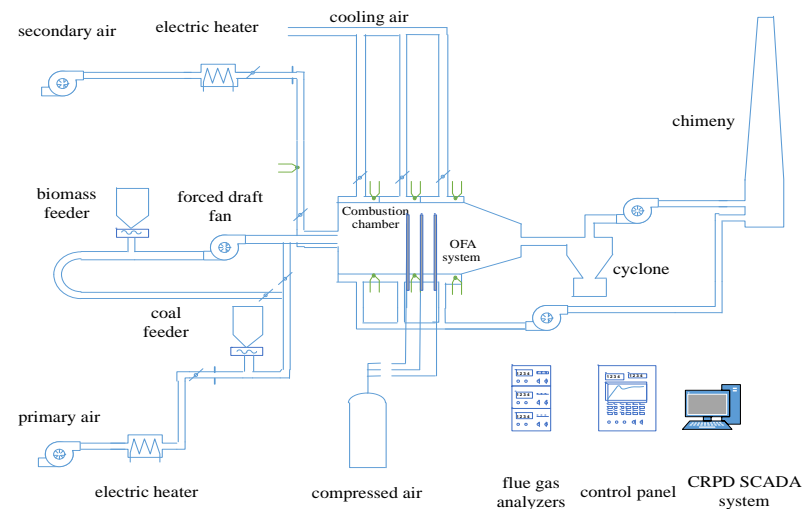

Fig. 2. Diagram illustrating the experimental stand for testing combustion processes

The central element of the station is a cylindrical combustion chamber, the inner part of which is covered with insulating material, and the external one is cooled with air. The front wall of the combustion chamber is cooled by water. A dust burner is installed in the front wall axis. The auxiliary oil burner is used to heat the station before the ignition of pulverized fuel. The primary air is supplied to the coal burner in the amount of $250 \mathrm{~m}^{3} \mathrm{~N} / \mathrm{h}$ and secondary air - up to $500 \mathrm{~m}^{3} \mathrm{~N} / \mathrm{h}$.

The identification of combustion process model parameters for a single low-emission burner was an essential element of the control system synthesis, including both diagnostic information and those from the optical flame monitoring system. In order to develop a mathematical model of the process, carried out with the use of a single low-emission burner, the measurements were carried out on the IEN test stand. The experiments included the stabilization of the working point of the laboratory stand at different powers, different types of fuel (including coal and biomass) and exchangeable three types of low-emission burners. Measurements of process variables were made at $1 \mathrm{~Hz}$. The registered values include multi-point measurements of exhaust gas concentrations $\left(\mathrm{NOx}, \mathrm{O}_{2}, \mathrm{CO}, \mathrm{CO}_{2}\right.$ ), measurements of temperatures, pressures, and flows as well as levels of air fans. Optical measurements on the flame were made at $1 \mathrm{kHz}$.

The initial stage of work included the analysis of selected, registered input and output quantities. For the synthesis of multidimensional models (MIMO), the vectors of input signals describing the secondary air flow, fuel output and output signal vectors including NOx concentration, $\mathrm{CO}$ and chamber temperature respectively were determined. The data were divided into training and testing sets, using a $70 \%$ and $30 \%$ distribution respectively. Using the System Identification Toolbox, parameters were identified for parametric models in the state space. The tested object was treated as a serial structure. Thus, the outputs of the models on the first level were the inputs for the second-level models and described the relationships between the NOx and $\mathrm{CO}$ concentrations, the temperature in the chamber and the corresponding values at the appropriate measurement point. Using the Matlab / Simulink platform tools, the MPC controller was designed, in order to test the credibility of the models obtained. Such an approach allows imposing boundaries on outputs and control signals, that interfered signals and prediction and control horizons. Thus, it allows checking the models in the context of normative restrictions (e.g. regarding NOx emissions).

The Simulink diagram of pulverized coal combustion process control system is presented in Figure 3. It allows modifications of the used models and the design of MPC controllers.

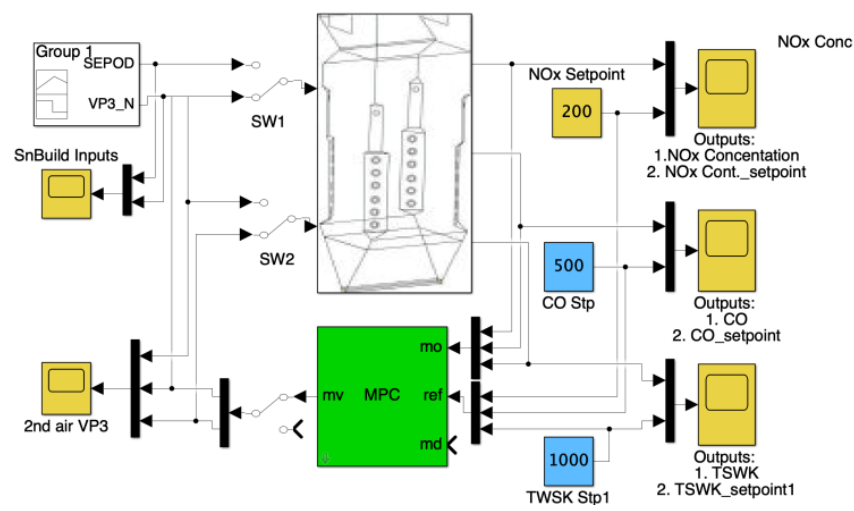

Fig. 3. Simulink diagram of the tested control system

As part of the conducted tests, taking into account the NOx emission standards restrictions ( $300 \mathrm{ppm})$, the best results in the sense of NRMSE were obtained for the low emission coal burner first (D1M1_4s6) and third (D3M1_4s3) model. Figure 4 gives an example of the analysis of the obtained results, for models $\mathrm{P} 1$ for with test data from the combustion process.

In the case of selected models (P2), compliance with emission limits was achieved with the occurring oscillations (D2M1_4s5), and in the case of (D2M1_4s6) - they were unsuccessful. The serial configuration yielded the best results in combination with model structures (D2M2_4s4 and D2M2_4s10). 


\section{Pulverized coal combustion and co-combustion with biomass process using optical signals from the flame}

Combustion tests were carried out on the Institute of Power Engineering test bench. A low-emission NOx burner mounted horizontally on the front wall of the chamber with a diameter of $0.1 \mathrm{~m}$. Previously prepared pulverized coal was stored in the bunker and delivered by a feeder. In case of biomass fuel, the coal dust was mixed with biomass (mainly with straw) in appropriate proportions.

There are inspection holes on both sides of the combustion chamber, allowing observation of the combustion process and providing data acquisition capability. As part of the research, a fast camera with a CMOS sensor was placed near the nozzle of the burner. The camera enabled image recording with a resolution of $1280 \times 1024$ pixels at a rate of 500 frames per second. The $0.7 \mathrm{~m}$ length borescope with camera set was used to record flame images. The optical system was cooled with a water jacket. In order to avoid contamination of the probe's lens, purified air purge was used. This operation was important due to the image registration but introduced minor disturbances in the area near the burner.

The course of the experiment required proper preparation, therefore the research was divided into several stages. Initially, the combustion chamber was heated with heating oil. After reaching the appropriate temperature level, pulverized coal was introduced into the burner with the primary air. The next phase was switching off the oil burner and introducing a mixture of coal and biomass. The coefficient of excess air was determined by the secondary air flow [3].
During the tests, nine variants were assumed, in which the thermal power (Pth) and the excess air coefficient $(\lambda)$ were set independently for the known biomass content. It should be noted that $\lambda$ is defined as the quotient of the combustion air weight $1 \mathrm{~kg}$ of fuel to the stoichiometric air mass.

The measurements were carried out for three heat power values $(250 \mathrm{~kW}, 300 \mathrm{~kW}$, and $400 \mathrm{~kW})$ at the object output and the specified values of the excess air factor $\lambda$, equal to $0.65,0.75$ and 0.85 , respectively. Besides, the tests included two fuel mixtures containing $10 \%$ and $20 \%$ straw-based biomass. The studies assumed fixed parameters of biomass physical properties (like particle size, natural humidity, etc.) as well as all image acquisition parameters (such as frame rate and time of exposure).

For the measurements carried out, an attempt was made to determine the optical parameters of the flame that can be used during diagnostics and control of the combustion process.

It was assumed that due to the need to develop an online control algorithm, the images from the camera were transformed by conversion to an 8-bit grayscale. The area of the flame in each frame of the obtained sequence was determined based on the amplitude of the pixels to distinguish the flame from other recorded objects in the field of view of the borescope. Thus, the sum of all bright pixels in the analysed flame determined its area. The coordinates $(\mathrm{x}, \mathrm{y})$ of the flame field center were calculated as the mean value of the coordinates of the lines or columns of all the pixels in the flame region, respectively. Flame contour length is defined as the sum of all envelope pixels, assuming that the distance between two adjacent contour points parallel to the coordinate axis has the value 1 .

In the proposed solution, the classic approach is supplemented with information about the flame based on selected image parameters registered with a fast camera.
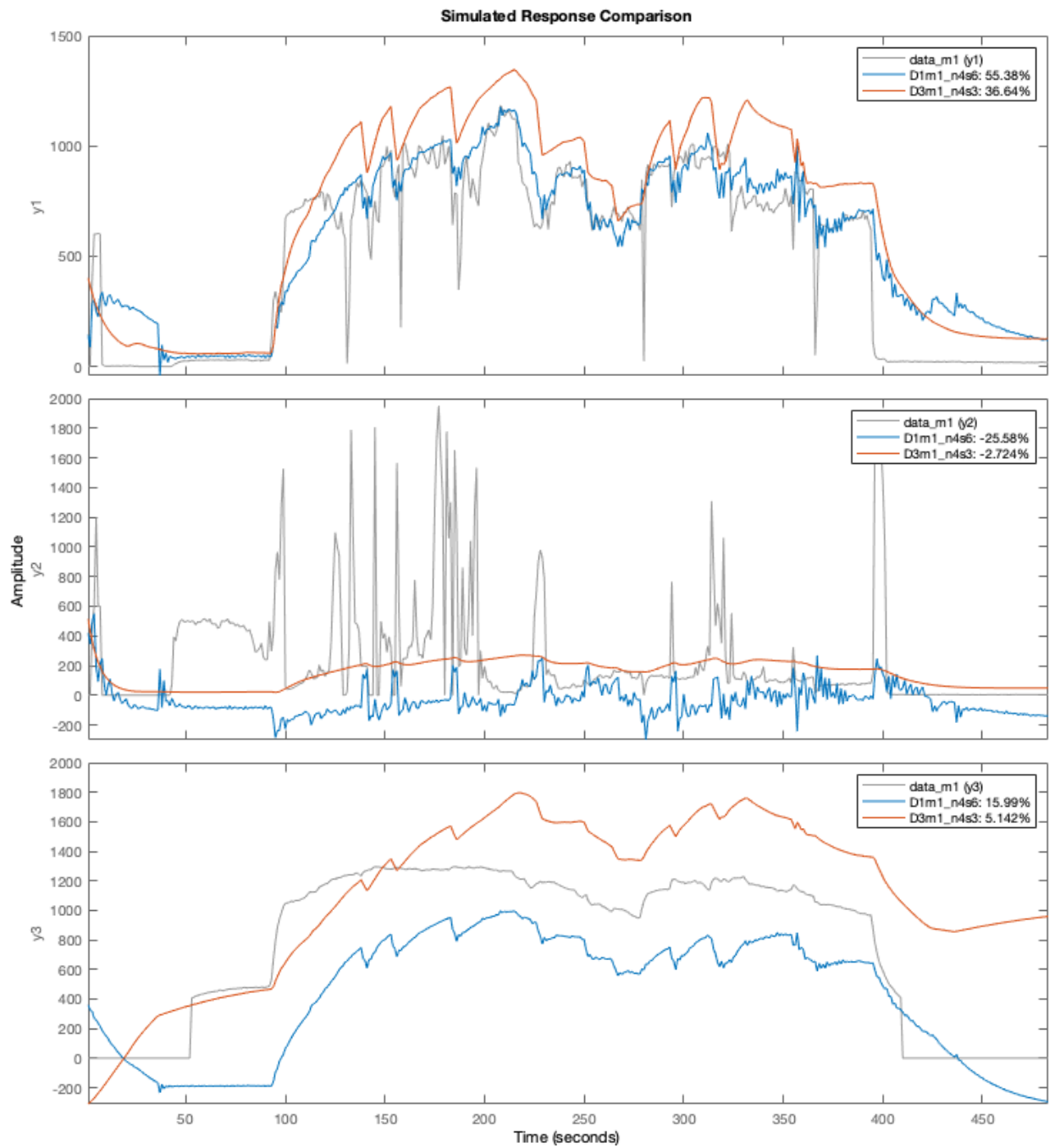

Fig. 4. Comparison of P1 model responses for test data from the combustion process 
As a result of the analysis, there was the relationship between the parameters describing changes in the flame image and the temperature of the flue gases and the amount of secondary air. Primary air is mainly used to supply coal dust to the nozzle of the burner, while secondary air is used to change the conditions of the combustion process (deviation from stoichiometry). The input parameters, such as the amount of fuel in the form of a coalbiomass mixture and air flows, were changed several times during tests to create different states of the combustion process.

An adaptive control seems to be a reasonable approach in case of incomplete knowledge about the controlled object or its rapid changes in operation.

The nonlinear autoregressive network with exogenous inputs (NARX) is a dynamic network with reverse connections including several layers. The NARX model is based on a linear ARX model, which is widely used in modeling time series. In the NARX model equation, each subsequent value of the dependent output signal is determined relative to the previous values of the output signal vector and the previous values of the independent (exogenous) input signal. The NARX model can be implemented using a forward-facing neural network to approximate a specific function. This implementation also allows for a vector ARX model in which input and output data can be multidimensional.

The outputs of the NARX network can be considered as an estimation of the results of the modeled non-linear dynamic system that are transmitted to the neural network input using feedback within the standard NARX architecture. Since the result is available during network training, it is possible to create a serial-parallel architecture (see [5]), in which the actual output is used instead of the estimated result. The custom architecture used for further analysis is the adaptive control algorithm (MRAC). This control architecture has two subnets. One subnet is a controlled process model, and the other subnet is a controller.

The trained NARX model can be used both to create the entire MRAC system and incorporate it inside the controller structure. In order for the closed loop MRAC system to respond in the same way as the reference model (used to generate data), the weights from the trained network should be placed in the MRAC system. The training of the MRAC system took much longer than training the NARX model because dynamic backward propagation was used in the network. After training procedures, the MRAC net- work was verified using test data. Two MRAC systems have been designed and compared. The first of them used a standard set of input vectors based on measurements, quantitatively describes the secondary air flow, the amount of fuel and vectors describing the air temperature in the chamber, recorded in the first measuring point, respectively. The second scheme used the secondary air flow control signal and the selected flame area descriptors. These optical information-based descriptors were determined using the Otsu method and the contour length. Figure 5 shows the system response to the input setpoint of the system in both cases: with standard measurements (a) and after using optical measurements in the form of a contour length vector for the flame descriptor (b). The simulation results shown in Figure 6 show that the output of the developed model follows the reference input with the correct, suppressed response, even if the input sequence was not the same as the input sequence in the training data. The steady state reaction may have an oscillating course at each stage, but this can be improved by using a larger training set and perhaps more neurons in the hidden layer. From the obtained results of the proposed adaptive control algorithm, it can be concluded that the constraints imposed on the values of control signals ensure stabilization of the process.

Nevertheless, the boundaries imposed on the signals will be a limitation also for the control system, because sudden changes in the process parameters may require the rapid reaction.

As mentioned above, imposing boundaries on signals can be a way to guarantee stability. The analyzed control system was subjected to a rapid step change of load, that illustrated the critical situation that may occur in case of an unexpected change in system parameters.

The algorithm took into account all the imposed boundaries, both on the controls and the outputs. The obtained results confirm its robustness, and thus the possibility of implementation in real systems. Boiler combustion efficiency and NOx emission are usually chosen as the main parameters of the target function in control with the SSN model. The neural model enables the mapping of dependencies between control parameters and outputs for different operating conditions. As a result, the control algorithm can be used as an advisory system for the operator or directly to control the combustion process in the boiler.
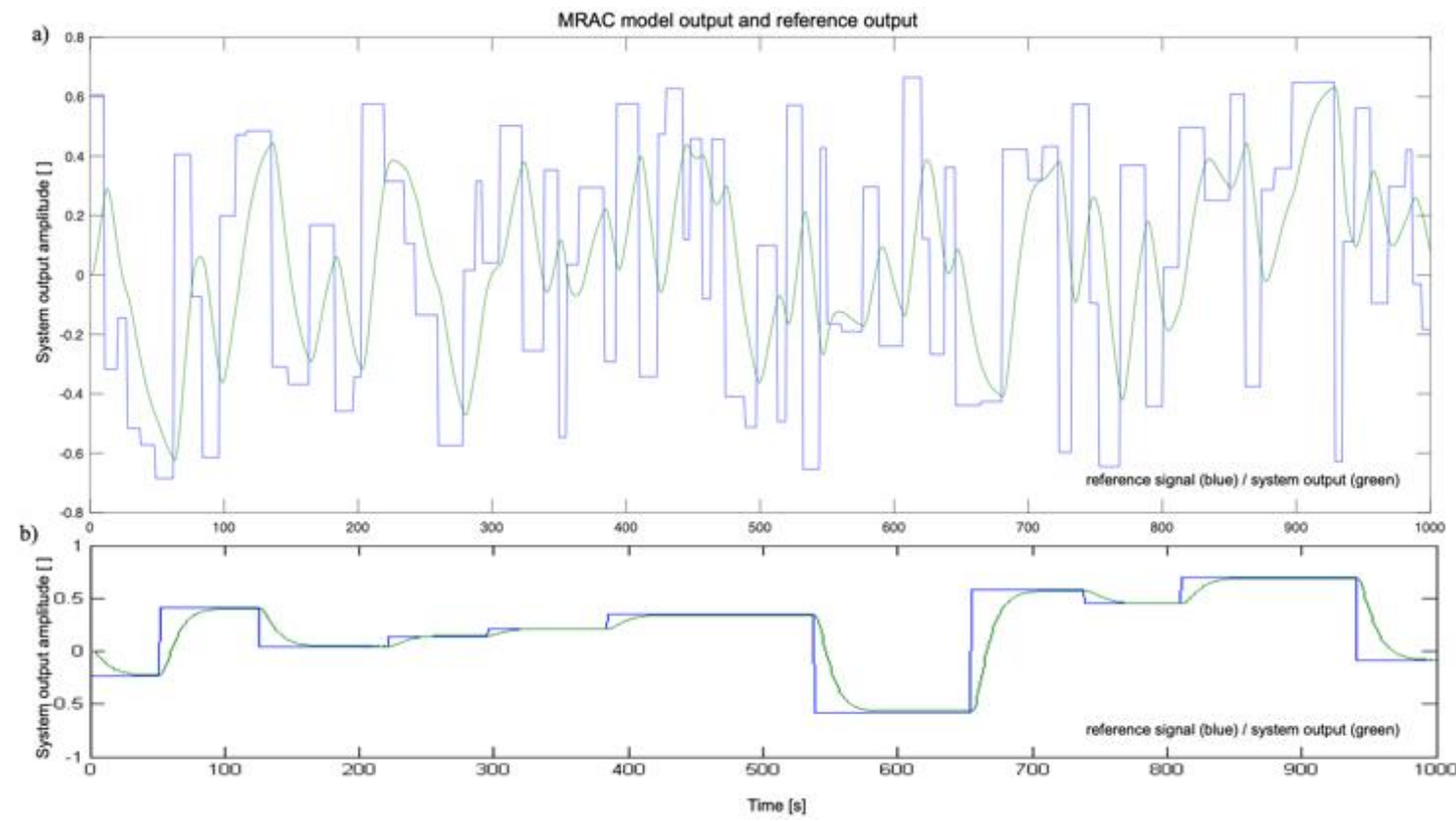


\section{Hybrid methods}

The attempt to solve the problem of identification and control of the strongly non-linear phenomenon related to the pulverized coal and biomass co-combustion was undertaken in the book "Advanced control techniques of pulverized coal combustion control".

The dynamics of this process is too complex to be modeled with a limited number of differential equations. Therefore, three selected structures of deep neural networks were considered for research: MLP, simple recursive network, and Long Short-Term Memory cells. Due to the unusually high variability of signals, the use of individual AI models is usually associated with getting stuck in local minima, and this leads to suboptimal solutions. It excludes obtaining satisfactory performance of the model in diagnostics and control tasks. However, in order to eliminate these limitations, hybrid algorithms are becoming more popular [10,11]. There are two main trends in the construction of hybrid models. One of them is a combination of several predictors, where their prediction results constitute a composite for final prediction.

\section{Conclusion}

Denote The results of tests and analyses presented in the monograph do not solve all of the problems associated with combustion process control. The issues of combustion dynamics with more detailed parametric stability analysis as well as conditions of turbulence require improvement. The control system may include other optical signals, including flame color and extension of hybrid methods with the use of fuzzy algorithms. According to the author, advanced control algorithms will be further developed and used in a wide range not only in industrial installations. One can risk the statement that these methods will shift towards the hybridization of artificial intelligence methods with other approaches.

\section{References}

[1] Bengio Y., Simard P., Frasconi P.: Learning Long-Term Dependencies with Gradient Descent is Difficult. IEEE Trans. Neural Networks 5/1994, 157-166.

[2] Computation N.: Long Short-term Memory. Neural Comput. 9/2016, 17351780 .

[3] Gromaszek K., Kotyra A., et al.: Signal Process. - Algorithms, Archit. Arrange. Appl. Conf. Proceedings SPA 3/2015, 133-136.

[4] Hopfield J.J.: Neural networks and physical systems with emergent collective computational abilities. Proc. Natl. Acad. Sci. 79/1982, 2554-2558.

[5] Kauranen P., Andersson-Engels S., Svanberg S.: Spatial mapping of flame radical emission using a spectroscopic multi-colour imaging system. Appl. Phys. B Photophysics Laser Chem. 53/1991, 260-264.

[6] Kordylewski W., Bulewicz E., Dyjakon A., Hardy T., et al.: Spalanie i Paliwa. Oficyna Wydawnicza Politechniki Wrocławskiej, Wrocław 2008.

[7] Lhner R.: Applied Computational Fluid Dynamics Techniques: An Introduction Based on Finite Element Methods. J. Fluid Mech. 1/2001, 375-376.

[8] Ordys A.W., Pike A.W., Johnson M.A., Katebi R.M., Grimble M.J.: Modelling and Simulation of Power Generation Plants, Springer-Verlag, 1994.

[9] Sepp H., Schmidhuber J.: Long short-term memory. Neural Comput. 9/1997, $1735-1780$.

[10] Tascikaraoglu A., Uzunoglu M.: A review of combined approaches for prediction of short-term wind speed and power. Renew. Sustain. Energy Rev. 34/2014, 243-254.

[11] Zhou H., Cen K., Fan J.: Multi-objective optimization of the coal combustion performance with artificial neural networks and genetic algorithms. Int. J. Energy Res. 29/2005, 499-510.

\begin{abstract}
Ph.D. Eng. Konrad Gromasze e-mail: k.gromaszek@ pollub.pl

Senior lecturer in Institute of Electronics and Information Technologies at Lublin University of Technology. Research field covers diagnosis and control algorithms as well as applications of artificial intelligence methods in industrial complex systems. Computer networks, PLC and mechatronics enthusiast.
\end{abstract}

ORCID ID: 0000-0002-3265-3714

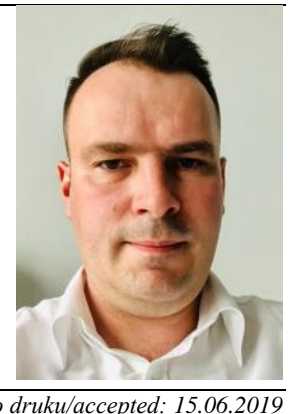

otrzymano/received: 15.05 .2019 przyjęto do druku/accepted: 15.06 .2019 